\title{
ENTRE O DEVER ESPECIAL E A LIBERDADE INDIVIDUAL: OS LIMITES OBJETIVOS DA RESPONSABILIDADE PENAL POR OMISSÃO NA RELAC,ÃO MÉDICO- PACIENTE
}

BETWEEN SPECIAL DUTY AND INDIVIDUAL FREEDOM: THE OBJECTIVES LIMITS OF THE CRIMINAL RESPONSIBILITY BY OMISSION IN THE MEDICAL-PATIENT RELATIONSHIP

Victor Cezar Rodrigues da Silva Costa ${ }^{1}$ PUC-PR

\section{Resumo}

O estudo pretende analisar as hipóteses que ensejam a posição de garante do médico, na intersecção existente entre o dever de atuar para a promoção da saúde do paciente e liberdade individual deste em se recusar ao tratamento indicado, a partir de um paradigma de respeito à autonomia do paciente. Tradicionalmente, tanto a doutrina quanto a jurisprudência entendem que, na hipótese de o médico deixar de atuar para salvar a vida do paciente sob seus cuidados, estaria caracterizada a posição de garantidor pela assunção voluntária do dever de evitar o resultado (art. 13, §2º, b, do Código Penal brasileiro). Propõe-se que a manifestação contrária do paciente em receber o tratamento descaracterizaria a imputação da possibilidade de agir do médico exigida pela posição de garantia, de forma a negar a sua especial vinculação

${ }^{1}$ Doutorando em Direito pela Pontifícia Universidade Católica do Paraná. Mestre em Direito Penal pela Universidade Federal de Minas Gerais. Professor de Direito Penal. Bolsista da CAPES. 
em relação a proteção do bem jurídico sob tutela. Para tanto, necessário se faz adotar uma visão não paternalista na relação médico-paciente.

Palavras-chave

Dogmática penal. Direito penal da medicina. Crimes omissivos impróprios. Posição de garantia. Imputação objetiva.

\section{Abstract}

This article aims to analyze the hypotheses in which the physician can be guarantor, at the intersection between the duty to act for the promotion of the patient's health and his individual freedom to refuse the indicated. Traditionally, both doctrine and jurisprudence understand that, in the event that the physician fails to act to save the patient's life under his care, the position of guarantor would be characterized by the voluntary assumption of the duty to avoid the result (art. 13, $\mathcal{S} 2$, b, of the Brazilian Penal Code). It is proposed that the contrary manifestation of the patient in receiving the treatment would mischaracterize the imputation of the possibility of the doctor's action required by the guarantee position, in order to deny his special position. Therefore, it is necessary to adopt a non-paternalistic view in the doctorpatient relationship.

Keywords

Criminal dogmatics. Criminal law in medicine. Improper omissive crimes. Guarantee position. Objective imputation.

\section{INTRODUÇÃO}

O esgotamento das discussões dogmáticas a respeito dos temas da parte geral reabriu espaço para discussão de temas específicos em Direito penal, dentre eles o Direito penal econômico e o Direito penal médico. No âmbito das intervenções médicas, e tendo em vista a relevância dos bens jurídicos envolvidos em seu trabalho, uma série de situações controversas podem ser verificadas. Na relação médicopaciente, verifica-se o paradoxo existente entre o dever de atuar para 
a promoção da saúde do paciente e liberdade individual deste em se recusar ao tratamento indicado. No tocante à incidência da norma criminalizadora sobre a atuação médica, pode-se vislumbrar tanto proibições em provocar lesões corporais ou impor um constrangimento ilegal àquele que está sob seus cuidados, quanto mandamentos de condutas, impondo-lhe deveres de salvamento e garantindo a vida do paciente.

O presente estudo se restringe a esta segunda hipótese. Isto é, pretende analisar as situações nas quais se pode afirmar configurada a posição de garantia do médico, seus limites formais e materiais, e as causas de seu afastamento. Sob um ponto de vista paternalista, impõese ao médico a manutenção da vida do paciente a qualquer custo, obrigando-lhe uma conduta de salvamento pela relação de proteção ao bem jurídico posto em seu cuidado. De outro lado, uma perspectiva orientada pela autonomia sustentará que o direito do paciente de recusar tratamentos afastaria a responsabilidade por omissão, inclusive obrigando o médico a deixar de atuar. ${ }^{2}$

Tradicionalmente, tanto a doutrina quanto a jurisprudência entendem que, na hipótese de o médico deixar de atuar para salvar a vida do paciente sob seus cuidados, estaria caracterizada a posição de garantidor pela assunção voluntária do dever de evitar o resultado (art. 13, §2º, b, do Código Penal brasileiro). No entanto, a primazia da autonomia sobre o dever especial de evitação da morte sob qualquer circunstância (art. 146, §3o, do CPB) impõe uma revisão do conteúdo

2 Sobretudo SIQUEIRA, Flávia. Autonomia, consentimento e Direito penal da medicina. São Paulo: Marcial Pons, 2019, p. 32. 
da posição de garantidor a partir de uma perspectiva normativa. A questão dogmática que perpassa essa discussão diz respeito a problemas práticos sobre o afastamento da responsabilidade do médico e sobre quais elementos caracterizadores da omissão imprópria recairiam.

\section{CARACTERÍSTICAS BÁSICAS DA POSIÇÃO DE GARANTIA}

A questão da imputação penal por omissão, sem sombra de dúvidas, ainda gera muitas discussões e controvérsias na dogmática penal. Mesmo não sendo um problema novo na doutrina em geral, a prática tem trazido à baila casos controversos no que toca à atribuição de responsabilidade. Hipóteses impensáveis em um direito penal democrático, ${ }^{3}$ ancorado na proteção subsidiária de bem jurídicos e no princípio da responsabilidade subjetiva. O retorno aos requisitos indispensáveis para a configuração do tipo objetivo dos crimes omissivos impróprios ou comissivos por omissão $0^{4}$, nesse sentido, se faz necessária para firmar os pressupostos sem os quais se pode ou não punir quem quer que seja por deixar de fazer algo. A doutrina tem

${ }^{3}$ No Brasil vide: ESTELLITA, Heloisa. Responsabilidade penal de dirigentes de empresas por omissão. São Paulo: Marcial Pons, 2017, p. 30. Vide também: COSTA, Victor. Crimes omissivos impróprios. Belo Horizonte: D’Plácido, 2017.

${ }^{4}$ Quanto à sua nomenclatura, vide o pioneiro estudo de MUNHOZ NETTO, Alcides. Os crimes Omissivos no Brasil. Curitiba: UFPR, 1982, p.23 e BRUNO, Anibal. Direito Penal. Parte Geral. Tomo II. Rio de Janeiro: Forense, 1981, p.219. Crítico em relação a denominação dos crimes omissivos impróprios ou comissivos por omissão e favorável a formula de Jescheck de omissão qualificada, vide TAVARES, Juarez. Teoria dos Crimes Omissivos. São Paulo: Marcial Pons, 2012, p. 312. 
apontado diversas exigências. Tradicionalmente apontam-se entre elas: a) de uma situação de perigo para o bem jurídico tutelado; b) da omissão da ação devida; c) evitação do resultado típico ${ }^{5}$; d) da posição de garantidor; e) da possibilidade de atuar para evitar o resultado. Correntes teóricas mais recente ainda incluem outros dois requisitos adicionais, quais sejam a) a causalidade e b) a imputação objetiva. ${ }^{6}$

Uma visão estritamente formalista da construção da omissão imprópria, fazendo referência à conjugação da norma proibitiva com a norma mandamental (contida na cláusula do art. 13, §2º da parte geral do Código Penal brasileiro), desconsidera qualquer substrato material em relação à norma penal. Em outras palavras, desestima sua função de proteção contra lesões ou exposições à perigos concretos a um bem jurídico penalmente tutelado, com base em uma finalidade racional de evitação de práticas danosas. ${ }^{7} \mathrm{Na}$ omissão imprópria, justamente pelo

${ }^{5}$ Vide BACIGALUPO, Enrique. Principios de Derecho Penal. Parte General.Madrid: Akal.1997, p.392.

${ }^{6}$ Especialmente em ROCHA, Ronan. A relação de causalidade no direito penal. Belo Horizonte: D’Plácido, 2017, p. 183. Dentre os autores que não exigem causalidade e imputação objetiva para a configuração dos delitos omissivos impróprios: FRAGOSO, Heleno. Lições de direito penal: parte geral. 16 ed. Rio de Janeiro: Forense, 2003, p. 290; REGIS PRADO, Luiz. Curso de direito penal brasileiro: parte geral. 5ạ ed. São Paulo: Revista dos Tribunais, 2005, p. 332; SANTOS, Juarez Cirino. Direito penal: Parte Geral. Florianópolis: Empório do Direito, 2017, pp. 204 e ss.

${ }^{7}$ ROXIN, Claus. A proteção de bens jurídicos como função do direito penal. Porto Alegre: Livraria do Advogado, 2009, pp. 18-19. Sobre a importância da necessidade de uma lesão de terceiros para a configuração de um bem jurídico penalmente relevante vide VON HIRSCH. Andrew. El concepto del bien jurídico y el "príncipio del daño". In HEFENDEHL, Roland. La teoria del bien jurídico. Madrid; Marcial 
fato de não possuir um tipo expresso na parte especial, é imprescindível a relação do omitente com determinado bem jurídico veiculado em um crime comissivo, em decorrência de um dever especial de proteção. ${ }^{8}$

Tal menoscabo ao bem jurídico não é possível de ser compatibilizado com a opção direcionada à funcionalização que o direito penal passou a admitir, principalmente depois da segunda metade do século XX. Desta maneira, no contexto de um Estado de Direito, extrai-se do texto constitucional, no âmbito dos direitos e garantias fundamentais, cláusulas materiais e invioláveis, impostas como limites ao poder estatal. A adoção de uma teoria material do dever coloca o conceito de bem jurídico no centro da discussão, exigindo a efetiva lesão ou ameaça de lesão a um bem jurídico para que fique constatada a existência de um dever exigível penalmente, não sendo suficiente a mera adequação formal normativa às hipóteses de garantidor.

Como lembra ainda Muñoz Conde, "omitir é um verbo transitivo, sempre que se omite se omite algo". ${ }^{9}$ Deixar de fazer, no sentido jurídico-penal, sempre possui como referência uma ação

Pons, 2007, p 37 e ss. Na literatura pátria a respeito do estado atual da teoria do bem jurídico vide COSTA, Helena Regina Lobo. Considerações sobre o estado atual da teoria do bem jurídico à luz do harm principle. In GRECO, Luis (Org) Direito penal como crítica da pena. Madrid: Marcial Pons, 2012, p. 133 e ss.

8 ESTELITTA, Heloisa, Responsabilidade penal de dirigentes de empresas por omissão, op. cit., 2017, p. 31.

9 MUÑOZ CONDE, Francisco; GARCÍA ARÁN, Mercedes. Derecho penal: Parte general. Valencia: Tirant lo Blanch, 1998, p. 266 e ss. Nossa tradução. 
mandada pela norma impositiva. Para o mesmo autor, "a omissão penalmente relevante, a nível do tipo de injusto do delito, é a omissão da ação esperada", ${ }^{10}$ logo, a ação imposta pela norma mandamental. Não se trata, a nosso ver, de referência à ação propriamente dita, mas sim ao dever de agir imposto pela norma. Consuma-se a omissão impura $^{11}$, ao nível típico, quando o agente, querendo ou não observando o cuidado requerido, deixa de atuar conforme $o$ mandamento normativamente previsto, produzindo um resultado lesivo ou concretamente perigoso ao bem jurídico protegido.

Diga-se, independentemente de qualquer base ideológica libertária ${ }^{12}$, não há um dever geral para que todos os indivíduos evitem resultados típicos produzidos por terceiros, o que tornaria insustentável a vida em sociedade. ${ }^{13}$ Nessa senda, em clara simpatia com a teoria formal do dever jurídico, previu-se no art. 13, $\S 2$ o do Código Penal, ser relevante a omissão apenas quando alguém: a) tenha por lei a obrigação de cuidado; b) por outra forma, assumiu a responsabilidade de evitar o resultado; ou ainda c) por comportamento anterior tenha criado risco de ocorrência de lesão. Entretanto, no estudo de cada uma dessas hipóteses é possível submeter a incidência

${ }^{10}$ MUÑOZ CONDE, Teoria geral do delito. Trad. Juarez Tavares e Luiz Regis Prado. Porto Alegre: Sérgio Fabris, p. 30.

${ }^{11}$ Quanto a opção pela expressão “omissão impura”, vide FIGUEIREDO DIAS, Jorge. Direito Penal. Parte Geral. Coimbra: Coimbra Editora/RT, 2007. p.913.

12 Vide NOZICK, Robert. Anarquia, Estado y Utopia. Madrid: Editorial Innisfree, 2015, p. 20 ess.

${ }^{13}$ Assim: ESTELITTA, Heloisa, Responsabilidade penal de dirigentes de empresas por omissão, op. cit., 2017, p. 31. 
da criminalização a limites específicos, sejam eles quanto a) à função do direito penal de protetor de bens jurídicos concretos (com a criação de deveres de assistência e proteção), seja quanto b) ao dever de vigilância sobre uma fonte de perigo (com mandamentos de controle e segurança). ${ }^{14}$

Na estrutura do delito omissivo impróprio como de infração de um dever é que surge a referência à chamada posição de garantidor. Segundo Bacigalupo, "não é um elemento de autoria exclusivo dos delitos impróprios de omissão, porque também nos delitos tipificados, nos quais se exige evitar um resultado, o omitente é garante" ${ }^{15}$ No entanto, quando se traz à discussão o dever de garantia, ainda não se

14 Acerca das teorias das funções na seara dos delitos impróprios de omissão: KAUFMANN, Armin. Dogmática de los delitos de omisión. Madrid: Marcial Pons, 2006, p. 289 e ss. Nesse sentido: MUÑOZ CONDE, Teoria geral do delito, op. cit., p. 36. Na mesma linha BUSATO, Direito penal, op. cit., p. 296. Também TAVARES, Teoria dos crimes omissivos. São Paulo: Marcial Pons, 2012. Referente ao critério material do dever de garante, denominando-o "domínio sobre a causa do resultado vide inicialmente SHÜNEMANN, Bernd. Fundamentos y límites de los delitos de omisión impropia. Madrid: Marcial Pons, 2009, p. 275 e ss. Ainda do mesmo autor: La responsabilidad por un delito impróprio de omisión. In Delincuencia empresarial: cuestiones dogmáticas y de Política Criminal. Buenos Aires: Fabian di Placido, 2004, p. 30 e ss. Mais recente vide ainda seu estudo "Sobre a posição de garantidor nos delitos de omissão imprópria - possibilidades histórico-dogmático, materiais e de direito comparado para escapar de um caos. In Estudos de Direito Penal, Direito Processual Penal e Filosofia de Direito. São Paulo: Marcial Pons, 2013, p.169 e ss. ${ }_{15}$ BACIGALUPO, Enrique. Delitos impropios de omisión. Buenos Aires: Pannedille, 1969, p. 263. No original: "no es un elemento de la autoría exclusivo de los delitos improprios de omisión, porque también en los delitos tipificados en los que se exige evitar un resultado el omitente es garante". 
está a tratar da imputação do resultado, mas tão só refere-se ao desvalor da conduta. A imputação, ao se tratar de um delito de resultado, depende necessariamente da lesão do bem jurídico penalmente tutelado. Além do que, se deve apurar se realmente havia condições e possibilidades fáticas da realização da ação que evitaria tal resultado (realização do risco no resultado), hipótese em que, se for impossível, nada se poderá imputar ao agente ou, sendo o caso, somente restará configurada a modalidade tentada. ${ }^{16} \mathrm{Com}$ as disposições relativas ao dever de garante, ficam estabelecidas as balizas dogmáticas sobre as quais se erigem o desvalor da conduta nos crimes omissivos impróprios. Por outro lado, há um requisito adicional exigido pelo art. $13, \S 2$ ㅇ, CP, isto é, a possibilidade física de agir. Esta liga-se não mais ao desvalor da conduta, mas mediatamente ao desvalor do resultado, em relação à sua evitação.

A aferição de tal circunstância deve ser pautada segundo "as condições, habilidades, deficiências ou especial informação do sujeito omitente e não de um suposto homem prudente". ${ }^{17}$ Bacigalupo, em estudo monográfico sobre o tema, contrariamente a Welzel e Kaufmann, aponta a possibilidade de evitar o resultado como pressuposto da posição de garante e não como seu limite. Para o autor,

16 Especialmente, no Brasil, vide GRECO, Luís. Problemas de causalidade e imputação objetiva nos crimes omissivos impróprios. Trad. Ronan Rocha. São Paulo: Marcial Pons, 2018. Também, anteriormente, em GRECO, Luis. Princípios fundamentais e tipo no novo projeto de Código Penal (Projeto 236/2012 do Senado Federal). Revista Liberdades (Publicação oficial do Instituto Brasileiro de Ciências Criminais). São Paulo, Edição Especial - Reforma do Código penal, 2012, p. 44. ${ }_{17}$ TAVARES, Teoria do crime culposo. Rio de Janeiro: Lumen Juris, 2009, p. 487. 
"se pode ser garante somente na medida em que se está em condições de evitar o resultado" ${ }^{18} \mathrm{O}$ dever, assim, somente diz respeito ao desvalor da ação, analisado segundo critérios ex ante. ${ }^{19}$ Sobre o desvalor do resultado, que se analisa ex post, nada é possível dizer apenas com a análise do dever de agir. Este, por seu turno, pode subsistir mesmo que não haja imputação do resultado referente à concreta posição de garantidor. ${ }^{20}$

Em relação à possibilidade de agir para evitar o resultado, Bacigalupo a divide em dois elementos sem os quais não é possível sequer analisar se o sujeito possuía ou não o dever de garantia: a) a possibilidade física real de evitação; e b) os pressupostos intelectuais da idoneidade da evitação. ${ }^{21}$ Assim, não se pode garantir a proteção de um bem jurídico além do que permitem os limites da própria realidade. Aqui opera a possibilidade física de atuar. Tal elemento funciona mediante um juízo hipotético, a ser verificado no caso concreto com base nos conhecimentos próprios da pessoa obrigada, em nível de probabilidade, em que a ação que deveria ser realizada pelo omitente teria evitado a lesão, com uma segurança próxima aos limites da

18 BACIGALUPO, Delitos impropios de omisión, op. cit., p. 111.

${ }^{19}$ GRECO, Luís. Princípios fundamentais e tipo no novo projeto de Código penal. In. LEITE, Alaor (org.) Reforma penal. A crítica científica à parte geral do projeto de Código penal. São Paulo: Atlas, 2015, p. 109. Originalmente em GRECO, Luís. Kausalität- und Zurechnungsfragen bei unechten Unterlassungsdelikt. Zeitschrift für Internationale Strafrechtsdodmatik, Aufgabe 8-9/2011, p. 676.

${ }^{20}$ ROCHA, A relação de causalidade no direito penal, op. cit., p. 184.

${ }^{21}$ BACIGALUPO, Delitos impropios de omisión, op. cit., p. 125. 
certeza. $^{22}$ Em outra vertente do mesmo fenômeno estão os pressupostos intelectuais, que se referem ao conhecimento do autor de determinadas circunstâncias em relação ao dever de garantia. Entre os elementos intelectuais, o que aqui nos interessa, seguindo as lições de Bacigalupo, seria o conhecimento da tipicidade, isto é, a percepção de que com determinada omissão possa-se lesionar um bem jurídico. Para o autor não basta apenas um "ter de conhecer" ou um "poder conhecer", mas uma consciência concreta da ação requerida pela norma mandamental, e não de qualquer outra. ${ }^{23}$ Ora, é de se questionar, nesse ponto, se a cognição do consentimento prévio do paciente afasta ou não a ação requerida pelo dever jurídico. Se o paciente nega o tratamento a ele oferecido, em que pese a própria lei penal brasileira apresentar causa de justificação para a atuação do médico quando em caso de iminente perigo de vida, a intervenção não se justificaria pela aposição de vontade contrária impeditiva de sua ação, de modo a afastar sua obrigação. De todo modo, esse é um raciocínio que somente se justifica a partir de uma correção normativa dos pressupostos de imputação dos crimes omissivos impróprios.

\section{A IMPUTAÇÃO DA OMISSÃO IMPRÓPRIA}

Desde Kaufmann, a limitação material da posição de garante, isto é, a submissão dos deveres formais à função de proteção de bens jurídicos e ao dever de vigilância sobre uma fonte de perigo tem o

22 BACIGALUPO, Delitos impropios de omisión, op. cit., p. 125.

${ }^{23}$ BACIGALUPO, Delitos impropios de omisión, op. cit., p. 126. 
papel de limitar o possível alargamento da atribuição do dever de agir, que permitiria, ao mais das vezes, responsabilidade penal pela mera posição. ${ }^{24}$

Outrossim, há de se ressaltar que não raras vezes, com o objetivo de restabelecer ou melhorar a saúde do paciente, o médico acaba por escolher técnicas que coloquem em perigo de lesão ou até mesmo lesem a integridade física do paciente. No Direito penal português a exclusão da responsabilidade penal do médico está prevista no art.150, I do Código Penal, segundo o qual se a conduta do médico se destinar a prevenir, diagnosticar, debelar ou minorar doença, lesão ou fadiga corporal, não há de ser considerada sua conduta como ofensa a integridade física. No tradicional Direito penal brasileiro esta situação estaria abrangida na hipótese de exclusão da ilicitude do exercício regular de um direito (lex artis), a partir de uma leitura estrita do art. 146, § 3o, do Código Penal brasileiro. ${ }^{25}$

Ocorre que o funcionalismo teleológico, na tentativa de superar tanto a teoria causalista quanto a finalista, alterou o conteúdo do tipo objetivo. Desde o causalismo naturalista, entende-se o tipo objetivo como o conjunto esquemático de ação, nexo causal e resultado. $\mathrm{O}$ finalismo pouco alterou esse esquema, apenas trouxe ao tipo o componente subjetivo consubstanciado na finalidade (dolo). A

${ }^{24}$ KAUFMANN, Armin. Dogmática de los delitos de omisión. Madrid: Marcial Pons, 2006, p. 289 e ss.

25 "§ 3o - Não se compreendem na disposição deste artigo: I - a intervenção médica ou cirúrgica, sem o consentimento do paciente ou de seu representante legal, se justificada por iminente perigo de vida; (...)". Sobre a doutrina tradicional vide SIQUEIRA, Autonomia, consentimento e direito penal da medicina, op. cit., p. 30. 
imputação objetiva vem justamente para promover a modificação dessa representação do tipo em ação, resultado e causalidade. ${ }^{26} \mathrm{E}$ este é, aqui, o ponto decisivo. Para que o fato seja considerado objetivamente típico - e aqui se inclui a omissão imprópria - seria imprescindível um conjunto de requisitos que fariam de uma causação (ou não impedimento do resultado), uma causação típica, violadora da norma, ou, em outras palavras, objetivamente imputável. ${ }^{27}$ Esses requisitos seriam: a) a criação ou o incremento de um risco juridicamente desaprovado; e b) a realização deste risco no resultado. No primeiro critério esbarrariam as ações que não criam ou aumentam riscos e as que, mesmo perigosas, respeitam as exigências de cuidado e são, por isso permitidas. No caso de intervenções cirúrgicas seguindo os preceitos da lex artis, o médico que age conforme as normas não teria praticado um homicídio. ${ }^{28}$

Não basta somente a criação ou incremento do risco, mas que o resultado seja decorrência desse risco, sendo o segundo critério a realização do risco. O exemplo é o famoso caso citado por manuais da vítima de um ferimento de bala que falece em virtude do tombamento da ambulância. O risco criado pelo autor do crime não se realizou no resultado, sendo substituído por outro. ${ }^{29}$ Com a teoria da imputação objetiva houve uma reestruturação do esquema do tipo objetivo, o qual

26 GRECO, Luís. Imputação objetiva: uma introdução. In. ROXIN, Claus. Funcionalismo e imputação objetiva no direito penal. 3a ed. Trad. Luís Greco. Rio de Janeiro: Renovar, 2002, pp. 6-7.

${ }^{27}$ GRECO, Imputação objetiva, op. cit, p. 7.

${ }^{28}$ GRECO, Imputação objetiva, op. cit, p. 8.

${ }^{29}$ GRECO, Imputação objetiva, op. cit, p. 8. 
aqui se seguirá, sendo a partir de agora necessário para sua caracterização, a ação/omissão, o nexo de causalidade, o resultado, a criação ou incremento de um risco juridicamente desaprovado e a realização deste risco no resultado. ${ }^{30}$

A imputação, portanto, obriga uma análise condicional de determinada conduta ter criado um risco juridicamente desaprovado de lesão a um bem jurídico. ${ }^{31}$ Sob essas circunstâncias, Roxin afirma categoricamente que a imputação do tipo objetivo só é um problema de parte geral nos casos dos denominados delitos de resultado, os quais exigem a ocorrência de um resultado lesivo no mundo exterior, dandose em um momento temporal e espacial distinto da ação, sendo certa a exigência do tipo penal da lesão para que haja a consumação do crime. ${ }^{32}$ Com base nessas premissas é possível diferenciar dois momentos primordiais: a imputação do comportamento e a imputação do resultado. No primeiro, Roxin considera o "comportamento pessoalmente imputável', isto é, o primeiro critério para que algo possa

${ }^{30}$ GRECO, Imputação objetiva, op. cit, p. 9.

${ }^{31}$ Roxin deriva a ideia de exposição a risco do conceito de bem jurídico. Cfr. ROXIN, Claus. Reflexões sobre a problemática da imputação em direito penal, p. 148. Sobre as bases epistemológicas da teoria de Roxin vide: ROXIN, Claus. Política criminal e sistema jurídico-penal. Trad. Luís Greco. Rio de Janeiro: Renovar, 2012.

${ }^{32}$ Nesse sentido ROXIN, Derecho penal (Tomo I), p. 345. Nas palavras de Roxin: "La imputación al tipo objetivo solo es un problema de la Parte general cuando el tipo requiere un resultado en el mundo exterior separado en el tiempo y el espacio de la acción del autor (...). En los delitos de mera actividad, como el allanamiento de morada (§123) o el falso testimonio (§154), la imputación al tipo objetivo se agota en la subsunción en los elementos del tipo respectivo que hay que tratar en la Parte especial" 
ser considerado como ação ou omissão. ${ }^{33}$ As causas de exclusão importam na ausência da imputação do comportamento. Já em uma segunda etapa, seria necessário acrescentar a imputação do resultado, determinante para dotar a conduta de conteúdo. Aqui estariam os critérios por ele pensados, com base na ideia de criação de um risco, para a atribuição do resultado. ${ }^{34}$

Os crimes omissivos impróprios, nesse sentido, decorrem do dever de evitar um resultado típico previsto em um tipo comissivo na parte especial. Partindo dessas conclusões prévias é que se pode afirmar que os critérios da teoria da imputação objetiva deveriam ser aplicados aos chamados delitos omissivos impróprios na nova conformação de seu tipo objetivo.

A situação em discussão, que diz respeito a abstenções consentidas, encontra-se na determinação de atos em que há o dever de atuar do médico e este se omite. Em consonância com a doutrina majoritária, tese segundo a qual já nos aderimos anteriormente, ${ }^{35} \mathrm{a}$ posição de garante do médico decorreria da assunção fática da função de proteção (art. 13, § 2o, b, do Código Penal brasileiro), o que decorreria do domínio sobre o desamparo da vítima, decorrente do ato de confiança do paciente. ${ }^{36}$

${ }^{33}$ ROXIN, Reflexões sobre a problemática da imputação em direito penal, p. 161. 34 Anteriormente em COSTA, Victor; SÁNCHEZ RIOS, Rodrigo. Causalidade e imputação objetiva nos crimes omissivos impróprios. In BUSATO, Paulo et al. (org.). Perspectivas das Ciências Criminais. Rio de Janeiro: GZ Editora, 2016, p. 530. ${ }^{35}$ COSTA, Victor. Crimes omissivos impróprios. Belo Horizonte: D` Plácido, 2017. 36 SIQUEIRA, Autonomia, consentimento e direito penal da medicina, op. cit., p. 386. 
Além disso, aderimos a posição de Siqueira, segundo a qual "o médico que respeita a vontade do paciente não cria um risco para sua vida, mas na verdade deixa de afastar um risco já existente" ${ }^{37}$. No âmbito da imputação haveria de se analisar, no entanto, se a conduta do médico incrementou ou não o risco da produção do resultado. Nos parece que deixar de fazer algo que poderia salvar a vida de um paciente, permitindo seu perecimento, aumenta o risco de um eventual resultado morte. Isso cria um problema se tentamos resolver o afastamento da responsabilidade no caso do consentimento do paciente a partir do ponto do desvalor da conduta.

A relevância penal da omissão surge como exigência de um comportamento para embasar a responsabilidade penal. A ausência de tal requisito permite a punição a partir de mera violação de deveres em divergência com a necessidade de lesão a um bem jurídico. Essa referência ao comportamento centra-se na voluntariedade da omissão, entendida como evitabilidade fundamentada na possibilidade de ação que evitaria o resultado. ${ }^{38}$

Todavia, importante lembrar que o fundamento de legitimidade da punição pela via da omissão há de repousar, em última análise, nos limites gerais da liberdade no que diz respeito à configuração do mundo. ${ }^{39}$ Nesse sentido, a liberdade do paciente há de ser considerada como causa impeditiva da possiblidade de agir do

${ }^{37}$ SIQUEIRA, Autonomia, consentimento e direito penal da medicina, op. cit., p. 385.

38 PALMA, Maria Fernanda. Direito Penal: Parte Geral. Lisboa: AAFDL, 2019, p. 72. ${ }^{39}$ PALMA, Maria Fernanda. Direito Penal: Parte Geral. Lisboa: AAFDL, 2019, p. 72. 
médico, a incidir sobre o desvalor do resultado. Em outras palavras, o risco é pré-existente à conduta do médico. A sua não-ação, de um modo ou outro, incrementa o risco da ocorrência do resultado. No entanto, o médico está impedido de atuar pela vontade contrária do paciente. Em que pese a possibilidade física de agir, desde Kaufmann, seja tratada como conceito ontológico, isto é, dependente da ação concreta de quem tenha o dever de atuar, ela é corrigida pelo raciocínio da imputação objetiva, especialmente no tocante a realização do risco no resultado.

Sob uma perspectiva pós-finalista, talvez em Schünemann, com sua teoria do domínio sobre o fundamento do resultado, ${ }^{40}$ se encontre a perspectiva normativa pela qual se possa delimitar a possibilidade física de agir. Segundo Aires de Souza, seguindo a linha do autor alemão, a obrigação de evitar o resultado demandaria: 1) o quadro de funções e competências que delimitam o dever de garantia; e 2) a possibilidade de cumprimento desses deveres identificada pelo domínio dos fatos ocorridos em seu espaço de responsabilidade, capazes de expor a perigo o bem jurídico tutelado. ${ }^{41} \mathrm{~A}$ possibilidade de agir, assim, estaria limitada pela ideia normativa de domínio, a restringir o dever e atuar como condição de existência da posição concreta de garantia. De todo modo, inegável a necessidade de

${ }^{40}$ SCHÜNEMANN, Bernd. Grund und Grenzen der unrechten Unterlassunsdelikte. Göttingen: Otto Schwartz Verlag, 1971, pp. 95 e ss. Na tradução em espanhol: SHÜNEMANN, Bernd. Fundamentos y límites de los delitos de omisión impropia. Madrid: Marcial Pons, 2009, p. 275 e ss.

${ }^{41}$ SOUZA, Susana Aires. Questões fundamentais de Direito Penal da Empresa. Lisboa: Almedina, 2019, p. 72. 
superação da possibilidade de agir como categoria meramente ontológica.

\section{CONCLUSÃO}

Propõe-se assim que a manifestação contrária do paciente em receber o tratamento descaracterizaria a possibilidade de agir do médico exigida pela omissão penalmente relevante, em especial pelo fato de afastar seu domínio por evitar a lesão a bem jurídico penalmente tutelado. Nega-se, assim, a especial vinculação do médico em relação ao resultado lesivo eventualmente produzido do bem jurídico posto sob sua tutela. Para tanto, uma revisão do conceito formal de garante adotado pelo direito penal brasileiro faz-se necessária à luz de uma visão não paternalista na relação médicopaciente. Isso decorre da exigência de um raciocínio de imputação objetiva na configuração do crime omissivo impróprio, caracterizado majoritariamente pela doutrina como crime de resultado.

Portanto, considerando serem a causalidade e a imputação objetiva requisitos indispensáveis para a caracterização do tipo objetivo nos delitos comissivos por omissão, o não-fazer no caso de negativa de autorização do paciente deve importar na descaracterização da realização do risco no resultado lesivo, em decorrência da limitação normativa da possibilidade de agir do médico pela vontade contrária do paciente pela ausência de domínio quanto ao fundamento do resultado. Da mesma forma, mesmo a hipótese de recusa de tratamento, a prestação de cuidados paliativos, como conduta alternativa conforme o direito, afastaria a imputação do resultado e, assim, a tipicidade quando assim o paciente o desejasse. 


\section{REFERÊNCIAS BIBLIOGRÁFICAS}

BACIGALUPO, Enrique. Delitos impropios de omisión. Buenos Aires: Pannedille, 1969.

BACIGALUPO, Enrique. Principios de Derecho Penal. Parte General.Madrid: Akal.1997.

BRUNO, Anibal. Direito Penal. Parte Geral. Tomo II. Rio de Janeiro: Forense, 1981.

COSTA, Helena Regina Lobo. Considerações sobre o estado atual da teoria do bem jurídico à luz do harm principle. In GRECO, Luis (org.). Direito penal como crítica da pena. Madrid: Marcial Pons, 2012. COSTA, Victor; SÁNCHEZ RIOS, Rodrigo. Causalidade e imputação objetiva nos crimes omissivos impróprios. In. BUSATO, Paulo; SÁ, Priscila; SCANDELARI, Gustavo (org.). Perspectivas das Ciências Criminais: coletânea em homenagem aos 55 anos de atuação profissional do Prof. René Ariel Dotti. Rio de Janeiro: GZ Editora, 2016.

COSTA, Victor. Crimes omissivos impróprios. Belo Horizonte: D`Plácido, 2017.

ESTELLITA, Heloisa. Responsabilidade penal de dirigentes de empresas por omissão. São Paulo: Marcial Pons, 2017.

FIGUEIREDO DIAS, Jorge. Direito Penal. Parte Geral. Coimbra: Coimbra Editora/RT, 2007.

FRAGOSO, Heleno. Lições de direito penal: parte geral. 16 ed. Rio de Janeiro: Forense, 2003. 
GRECO, Luís. Imputação objetiva: uma introdução. In. ROXIN, Claus. Funcionalismo e imputação objetiva no direito penal. 3a ed. Trad. Luís Greco. Rio de Janeiro: Renovar, 2002.

GRECO, Luís. Kausalität- und Zurechnungsfragen bei unechten Unterlassungsdelikt. Zeitschrift für Internationale Strafrechtsdodmatik, Aufgabe 8-9/2011.

GRECO, Luís. Princípios fundamentais e tipo no novo projeto de Código Penal (Projeto 236/2012 do Senado Federal). Revista Liberdades (Publicação oficial do Instituto Brasileiro de Ciências Criminais). São Paulo, Edição Especial - Reforma do Código penal, 2012.

GRECO, Luís. Problemas de causalidade e imputação objetiva nos crimes omissivos impróprios. Trad. Ronan Rocha. São Paulo: Marcial Pons, 2018.

KAUFMANN, Armin. Dogmática de los delitos de omisión. Madrid: Marcial Pons, 2006.

MUNHOZ NETTO, Alcides. Os crimes omissivos no Brasil. Curitiba: UFPR, 1982.

MUÑOZ CONDE, Francisco; GARCÍA ARÁN, Mercedes. Derecho penal: Parte general. Valencia: Tirant lo Blanch, 1998.

MUÑOZ CONDE, Teoria geral do delito. Trad. Juarez Tavares e Luiz Regis Prado. Porto Alegre: Sérgio Fabris.

NOZICK, Robert. Anarquia, Estado y Utopia. Madrid: Editorial Innisfree, 2015.

PALMA, Maria Fernanda. Direito Penal: Parte Geral. Lisboa: AAFDL, 2019.

REGIS PRADO, Luiz. Curso de direito penal brasileiro: parte geral. 5a ed. São Paulo: Revista dos Tribunais, 2005. 
ROCHA, Ronan. A relação de causalidade no direito penal. Belo Horizonte: D’Plácido, 2017.

ROXIN, Claus. A proteção de bens jurídicos como função do direito penal. Porto Alegre: Livraria do Advogado, 2009.

ROXIN, Claus. Reflexões sobre a problemática da imputação em direito penal. In. ROXIN, Claus. Problemas fundamentais do direito penal. Trad. Ana Paula Natscheradetz. Lisboa: Vega, 2004.

ROXIN, Claus. Derecho penal: Parte general. Tomo I. Trad. DiegoManuel Luzón Peña; Miguel Díaz y García Colledo e Javier de Vicente Remesal. Madrid: Civitas, 2001.

SANTOS, Juarez Cirino. Direito penal: Parte Geral. Florianópolis: Empório do Direito, 2017.

SCHÜNEMANN, Bernd. La responsabilidad por un delito impróprio de omisión. In Delincuencia empresarial: cuestiones dogmáticas y de Política Criminal. Buenos Aires: Fabian di Placido, 2004.

SCHÜNEMANN, Bernd. Sobre a posição de garantidor nos delitos de omissão imprópria - possibilidades histórico-dogmático, materiais e de direito comparado para escapar de um caos. In Estudos de Direito Penal, Direito Processual Penal e Filosofia de Direito. São Paulo: Marcial Pons, 2013.

SCHÜNEMANN, Bernd. Grund und Grenzen der unrechten Unterlassunsdelikte. Göttingen: Otto Schwartz Verlag, 1971.

SCHÜNEMANN, Bernd. Fundamentos y límites de los delitos de omisión impropia. Madrid: Marcial Pons, 2009.

SIQUEIRA, Flávia. Autonomia, consentimento e Direito penal da medicina. São Paulo: Marcial Pons, 2019.

SOUZA, Susana Aires. Questões fundamentais de Direito Penal da Empresa. Lisboa: Almedina, 2019. 


\section{DELICTAE, Vol. 5, No8, Jan..-Jun. $2020 \mid 312$}

TAVARES, Juarez. Teoria do crime culposo. $3^{\mathrm{a}}$ ed. Rio de Janeiro: Lumen Juris, 2009.

TAVARES, Juarez. Teoria dos Crimes Omissivos. São Paulo: Marcial Pons, 2012.

VON HIRSCH. Andrew. El concepto del bien jurídico y el "príncipio del daño". In HEFENDEHL, Roland (org.). La teoria del bien jurídico. Madrid; Marcial Pons, 2007. 